\title{
Affecting glass fibre surfaces and composite properties by two stage sizing application
}

\author{
R.-C. Zhuang1, T. Burghardt ${ }^{2}$, R. Plonka ${ }^{1}$, J.-W. Liu ${ }^{1}$, E. Mäder ${ }^{*}$ \\ ${ }^{1}$ Leibniz Institut für Polymerforschung Dresden, Hohe Straße 6, 01069 Dresden, Germany \\ 2Johns Manville Technical Center, 10100 West Ute Ave., Littleton CO 80127, USA
}

Received 24 June 2010; accepted in revised form 3 September 2010

\begin{abstract}
The influence of sizing constituent distribution on the properties of sized glass fibres (GFs) and corresponding polypropylene (PP) composites was studied by two-stage sizing application, i.e. applying silane coupling agent and polymeric film former at separate stages and with different sequences, in comparison with one-stage sizing application usually used. Surface properties of sized GFs and transverse tensile strength of unidirectional GF reinforced composites were studied using various surface and interface analysis methods and tensile testing, respectively. Two-stage technology achieved sized GFs with lower loss-on-ignition (LOI) and resulted in poor fibre-matrix adhesion strength. However, applying silane coupling agent at the first sizing stage with an increased roller speed achieved sized GFs with lower LOI but composites with mechanical properties quite close to those of composites based on one-stage technology. Moreover, the difference in surface properties of sized GFs is discussed in terms of the wetting ability difference of sizing constituents and the interactions between sizing components.
\end{abstract}

Keywords: polymer composites, glass fibre, polypropylene, sizing, mechanical properties

\section{Introduction}

In last few decades, intensive research efforts have been devoted, especially, to achieve a better understanding of the interphase between reinforcement and matrix since the mechanical properties of composite materials highly depend on the interphase properties [1-3]. Interphases between reinforcement and matrix are formed by the inter-diffusion of sizing and matrix [4], resulting in different compositions and properties compared to the bulk matrix. Interphases with gradual or monotonic change of mechanical properties and composition rather than homogeneous properties are highly expected, since in such case mechanical stresses can be efficiently transferred from matrix to reinforcement and the concentration of mechanical and thermomechanical stresses at this area can be greatly avoided [5]. Recent progresses in mechani- cal characterisation on interphases in combination with adhesion strength measurement and real composite mechanical tests indicated the presence of an interphase with mechanical property gradients leading to high mechanical properties [6-11].

As there is a steadily increasing interest in the use of thermoplastic composites in different fields, such as construction, automotive industries and aeronautic industries, in the field of GF reinforced thermoplastic composites various strategies have been developed in order to tailor the interphase characteristics, which mainly focused on the modification of GF surface or matrix, aiming at enhancing the GF-matrix adhesion strength, such as by enhancing GF-matrix compatibility, mechanical interlocking, and acid-base interaction [1-3, 1214]. From the viewpoint of production, on-line surface modification of the as-spun GF with an appro- 
priate sizing (generally a mixture of silane coupling agent, polymeric film former and additives) is a straightforward strategy for tailoring the interphase properties to give cost-effective composite materials [14-25]. Thus, great attentions have been paid on the sizing structure or radial chemical composition to deepen the understanding of the correlation between the mechanical properties of composites and both the sizing and sizing technology. Post treatments and analyses [3, 26-32] on model reinforcements, especially 3-aminopropyltriethoxysilane $(\gamma$-APS) sized GF or silica, revealed that the surface of $\gamma$-APS sized model reinforcements consists of three layers, which are physically adsorbed, chemisorbed, and chemically covalent bonded polysiloxanes from air/sizing interface to sizing/GF interface [29-31]. It was found that the physically adsorbed polysiloxanes based on $\gamma$-APS have a detrimental effect on the GF-matrix adhesion strength [33]. Moreover, the sizing conditions, such as $\mathrm{pH}$ value and sizing concentration, can affect the detailed molecular structures of sizing and consequently the composite performance [28, 34]. For real reinforcements sized with the complete sizing formulation, it was proposed that silane coupling agent enriches on the sizing/GF interface, while the polymeric film former predominates on the sizing/ air interface, hence polymeric film former and polysiloxane network form an interpenetrating network (IPN) with gradual change of chemical composition from silane coupling agent dominated phase to polymeric film former enriched phase [29, 35].

Literature addressing the formation of interphase dependence of sizing structure based on the complete sizing package is very limited [9-11, 36]. In this study, silane coupling agent and polymeric film former were applied sequentially on as-spun GF at different stages, i.e. firstly applying silane coupling agent and then polymeric film former or firstly applying polymeric film former and then silane coupling agent. Using such a strategy, one is able to 1) create silane coupling agent enriched sizing/GF interface and polymeric film former dominated sizing/air interface or inverse for the study of the interdiffusion behaviour of different sizing components during the processing, 2) study the pickup and/or adsorption/desorption behaviour of sizing components, and 3) study the influence of these two aspects on the properties of sized GFs and corresponding composites.
Furthermore, stepwise sizing application technology might lead to potential saving by reducing the LOI of GFs while maintaining the composite performance since the sizing is one of the major contributors to the cost of composites. The LOI of sized GFs can be adjusted by many factors, such as sizing application roller speed, the wetting properties (surface tension, charge, concentration, and viscosity and so on) of sizing, and drying temperature [21]. To the best of our knowledge, so far no report describes the use of multi-stage sizing application for this purpose. The idea behind this is to reduce the pickup of sizing constituents by lowering the sizing concentration.

\section{Experimental Details}

\subsection{Materials}

GF with average diameter of $15 \mu \mathrm{m}$ (204 filaments, yarn fineness of 90 tex) were spun at the Leibniz Institute of Polymer Research Dresden using a continuous spinning device comparable to industrial ones. The take-up speed was kept constant at $750 \mathrm{~m} / \mathrm{min}$, water cooling spray was considered unnecessary in order to avoid change in concentration. The bobbin weight was kept constant at $600 \mathrm{~g}$ and dried at $125^{\circ} \mathrm{C}$ for $4 \mathrm{~h}$. For the preparation of PP compatibly sized GF, maleic anhydride grafted PP (MAH-g-PP) dispersion (35 wt.\% solid content, number average molecular weight is $81300 \mathrm{~g} / \mathrm{mol}$ ) was used as film former and $1 \mathrm{wt} . \% \gamma$-APS water solution was used as silane coupling agent at the native $\mathrm{pH}$. In two stage sizing application technology (referred to as two-stage technology), the second sizing application stage (referred to as the second stage) was placed about $50 \mathrm{~cm}$ below the first sizing application stage (referred to as the first stage). The applicator rolls were positioned both on one side of the spread single filaments of the strand. Table 1 summarizes the information on the sizing application of the sized GFs. M1 fibre was produced by applying $\gamma$-APS solution at the first stage and PP dispersion at the second stage with sizing application conditions (applicator roll speed of $14.1 \mathrm{~m} / \mathrm{min}$ ) commonly used in industrial production (referred to as standard conditions), while a higher rotation speed $(17.6 \mathrm{~m} / \mathrm{min})$ was applied for the first sizing applicator to give M1W fibre. M2 fibre was obtained by using reverse sizing application sequence in comparison with M1 fibre 
Table 1. Summary of sizing application and surface properties of sized glass fibres

\begin{tabular}{|c|c|c|c|c|c|c|c|c|}
\hline \multirow{2}{*}{ GF } & \multicolumn{2}{|c|}{ Sizing components and application sequence } & \multirow{2}{*}{$\begin{array}{c}\text { LOI } \\
\text { [wt.\%] }\end{array}$} & \multicolumn{2}{|c|}{ Roughness [nm] } & \multicolumn{3}{|c|}{ Contact angle with water $\left[{ }^{\circ}\right]$} \\
\hline & $1^{\text {st }}$ stage & $2^{\text {nd }}$ stage & & $\mathbf{R}_{\mathbf{q}}$ & $\mathbf{R}_{\max }$ & $\theta_{\mathrm{a}}$ & $\theta_{\mathrm{r}}$ & $\theta_{\mathrm{a}}-\theta_{\mathrm{r}}$ \\
\hline APS & $\gamma$-APS $(64-68)^{1}$ & & $0.05 \pm 0.02$ & $0.8 \pm 0.5$ & $17.7 \pm 13.8$ & $83.5 \pm 2.9$ & $56.8 \pm 4.3$ & 26.7 \\
\hline $\mathrm{PF}$ & PP dispersion $(33.7)^{1}$ & & $0.23 \pm 0.01$ & $2.1 \pm 1.1$ & $40.5 \pm 16.0$ & $58.1 \pm 2.0$ & $41.6 \pm 3.9$ & 16.5 \\
\hline M1 & $\gamma$-APS & PP dispe & $0.30 \pm 0.02$ & $16.1 \pm 7.2$ & $135.9 \pm 35.6$ & $77.7 \pm 2.3$ & $49.1 \pm 4.2$ & 28.6 \\
\hline M2 & PP dispersion & $\gamma$-APS & $0.30 \pm 0.01$ & $4.9 \pm 1.5$ & $67.8 \pm 32.2$ & $73.2 \pm 2.2$ & $45.7 \pm 2.5$ & 28.5 \\
\hline M3 & $\gamma$-APS+PP dispersion $(35.3)^{1}$ & & $0.54 \pm 0.002$ & $5.8 \pm 1.8$ & $74.5 \pm 19.4$ & $84.5 \pm 2.1$ & $58.1 \pm 2.6$ & 26.4 \\
\hline${\mathrm{M} 1 \mathrm{~W}^{2}}^{2}$ & $\gamma$-APS & PP dispersion & $0.37 \pm 0.003$ & $18.6 \pm 2.7$ & $155.1 \pm 46.1$ & $84.2 \pm 3.4$ & $49.2 \pm 6.2$ & 35.0 \\
\hline
\end{tabular}

${ }^{1}$ the numbers in parentheses are the surface tensions of sizing components, the unit is $\mathrm{mN} / \mathrm{m}$.

${ }^{2}$ using increased first applicator roll speed

while the same sizing application conditions were used. M3 fibre was spun using the one-stage technology commonly used. For a better comparison, GFs sized with $\gamma$-APS or PP dispersion were also prepared and referred to as APS and PF fibres, respectively. Homo-PP compounded with 2 wt.\% $\mathrm{MAH}-\mathrm{g}$-PP was used as matrix for the preparation of hybrid PP/GF yarn with 50 vol.\% GF for continuous fibre composites, as described in detail elsewhere [37]. The unidirectional fibre-reinforced polymer composites made of commingled yarns were processed in computer controlled identical long-term cycles (heating, consolidation, and cooling in the mould) at a temperature of $225^{\circ} \mathrm{C}$ and a pressure of $3 \mathrm{MPa}$.

\subsection{Characterizations}

The LOI of sized GFs was determined according to ASTM D4963-04 by means of high temperature pyrolysis at $625^{\circ} \mathrm{C}$.

Atomic force microscopy (AFM, Digital Instruments D3100, Santa Barbara, USA) was used to determine the surface roughness and topography of sized GFs. The presented roughness data are averaged values based on 12 specimens each 3 on different fibres, the $2^{\text {nd }}$ order plane fitting was performed prior to roughness measurement.

Electrokinetic properties of $\gamma$-APS solution, PP dispersion and corresponding sizing were studied using a Mütek PCD 03. Electrokinetic properties, Zeta-potential as a function of $\mathrm{pH}$, of sized GFs were obtained by electrokinetic analysis (EKA) on an electrokinetic analyzer (Fa. Anton Paar KG, Austria).

Particle size distribution of $\gamma$-APS solution, PP dispersion and corresponding sizing was studied on a Zetasizer nano ZS (Malvern Instruments $\mathrm{GmbH}$, Herrenberg, Germany).
The dynamic advancing contact angle $\left(\theta_{a}\right)$ and receding contact angle $\left(\theta_{r}\right)$ measurements on single GFs were performed on a tensiometer K14 (Krüss $\mathrm{GmbH}$, Hamburg, Germany) using water as measurement liquid. The presented results are averaged values based on 15 specimens. The surface tensions of the aqueous solutions/dispersions were determined by using a platinum plate on the same equipment.

XPS investigations were performed on a Kratos AXIS Ultra X-ray photoelectron spectrometer $(X P S)$. Areas of approximately $300 \times 700$ microns were analyzed with a monochromatic $\mathrm{Al} \mathrm{K}_{\alpha} \mathrm{X}$-ray source. The survey spectra were collected over a wide binding energy range $(0-1300 \mathrm{eV})$ and were used to evaluate all of the elements present (except $\mathrm{H}$ and $\mathrm{He}$ ) within the sample surface. The survey spectra were acquired at 6 areas with a pass energy of $160 \mathrm{eV}$ and a step size of $1 \mathrm{eV}$. The parameters of the component peaks were their binding energy, height, full width at half maximum and the Gaussian-Lorentzian ratio.

The transverse tensile strength of unidirectional (UD) GF/PP composites was measured according to specification ISO 527 with a velocity of $1 \mathrm{~mm} / \mathrm{min}$, whereas cap strips are applied on the ends of the specimens $(2 \times 10 \times 140 \mathrm{~mm})$. The presented results are averaged values based on 10 specimens for each test series.

\section{Results and discussion}

\subsection{Analysis on sizings}

In order to better understand the formation of different sizing structures using different sizing application sequences, dynamic light scattering and particle charge detection were used to study the particle size distribution and streaming potential as a function of $\mathrm{pH}$ for $\gamma$-APS solution, PP dispersion 

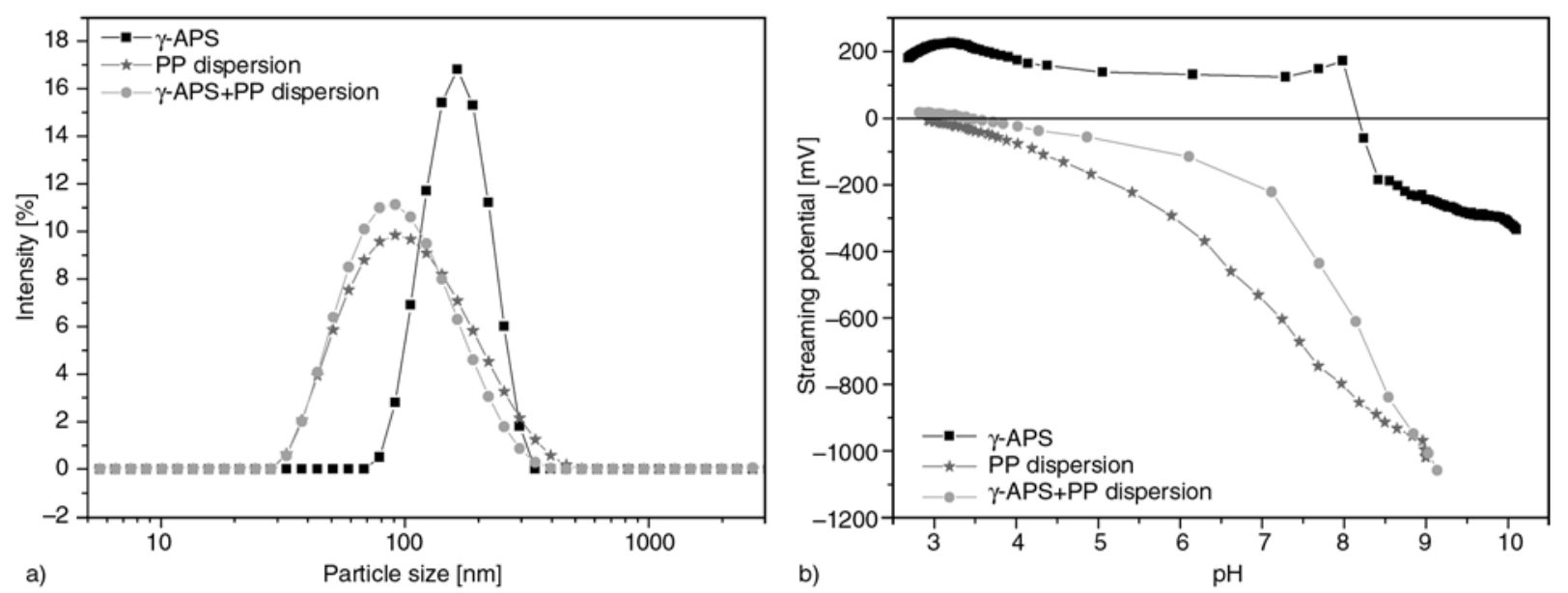

Figure 1. Pre-examination on $\gamma$-APS solution, PP dispersion and corresponding sizing: a) particle size distribution curves and $\mathrm{b}$ ) streaming potential as a function of $\mathrm{pH}$

and corresponding sizing, the results are shown in Figure 1a and 1b, respectively. Figure 1.a shows: 1) The hydrolyzed $\gamma$-APS molecules further oligomerized and aggregated to form aggregations with average particle diameter of around $110 \mathrm{~nm}$. 2) The PP dispersion has a narrow mono-modal particle size distribution curve with a peak centered at around $90 \mathrm{~nm}$. 3) Mixing PP dispersion with $\gamma$-APS solution hardly led to any apparent change, the particle size distribution of the resulting mixture is quite similar to that of pure PP dispersion. In Figure $1 \mathrm{~b}$, one can find that the $\gamma$-APS based micelle is negatively charged at its native $\mathrm{pH}$ of 10.6 , the isoelectric point (IEP) of $\gamma$-APS solution is about 8.2. PP dispersion also possesses a negative streaming potential with an absolute value of $1198 \mathrm{mV}$ at the native $\mathrm{pH}$ of 9, the IEP of $\mathrm{PP}$ dispersion is around $\mathrm{pH}$ 3. FTIR analysis on the solid part of PP dispersion (results not shown) showed the absorption band of maleic anhydride group at around $1783 \mathrm{~cm}^{-1}$ [36]. It is known that the pKa values of succinic acid are about 4.2 and 5.5 [38], however the dense PP particles may limit the accessibility of acid groups [39], hence that the IEP of PP dispersion shifts to a lower $\mathrm{pH}$ range is reasonable. It is noted that adding $\gamma$-APS solution to PP dispersion led to a little bit more negative streaming potential of $1248 \mathrm{mV}$ maybe due to the change of $\mathrm{pH}$, meanwhile the IEP shifts to more basic of $\mathrm{pH} 3.8$.

\subsection{Surface properties of sized GFs}

The pick-up of sizing constituents onto GFs was studied by pyrolysis at $625^{\circ} \mathrm{C}$. Table 1 summarizes the average LOI values of differently sized GFs. It is noted that APS and PF fibres have LOI of 0.05 and $0.23 \mathrm{wt} . \%$, respectively. One-stage technology resulted in M3 fibre with the highest LOI value of 0.54 wt.\%. Two-stage technology led to sized GFs, M1, M1W and M2 fibres, with lower LOI values in the range of $0.30-0.37 \mathrm{wt} . \%$. Additionally, it is noted that either applying firstly $\gamma$-APS solution (M1 fibre) or applying firstly PP dispersion (M2 fibre) did not have a great influence on the LOI value of sized GFs, both sequences resulted in sized GFs with LOI value at the same level.

Tapping mode AFM was used to study the surface morphology of sized GFs, Figure 2 presents the AFM height images and the corresponding schematic topographies. Surface roughness in terms of root mean square roughness $\left(R_{q}\right)$ and maximum roughness $\left(R_{\max }\right)$ with their standard deviation is summarized in Table 1. The surface of APS fibre is quite smooth with $R_{q}$ of $0.8 \mathrm{~nm}$ and featureless except $\gamma$-APS based polysiloxane islands. PF fibre also possesses a relative smooth surface, the $R_{q}$ and $R_{\max }$ are 2.1 and $40.5 \mathrm{~nm}$, respectively. Two-stage technology by applying PP dispersion at the second stage resulted in sized GFs with rough surfaces characterized by pine bark-like morphology, both M1 and M1W fibres have high $R_{q}$ and $R_{\max }$ values with high standard deviation, the latter one has slightly higher $R_{q}$ and $R_{\max }$ values. Two-stage technology by applying PP dispersion at the first stage and one-stage technology achieved sized GFs with smoother surface, whereas their surfaces are still rougher than those of APS and PF fibres, but quite similar to that of one-stage technology. The differ- 

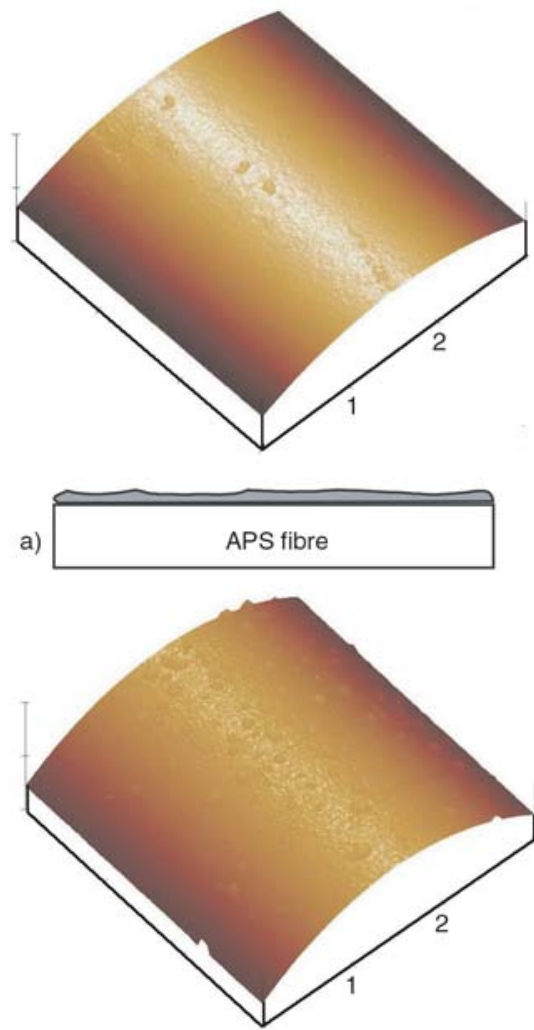

d)

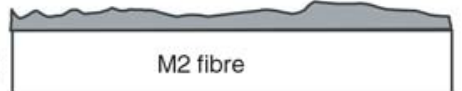

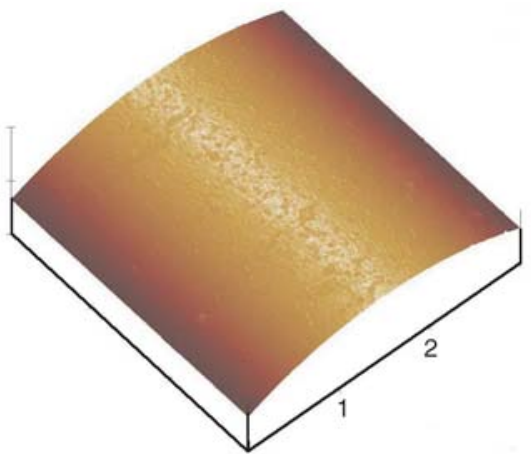

b)
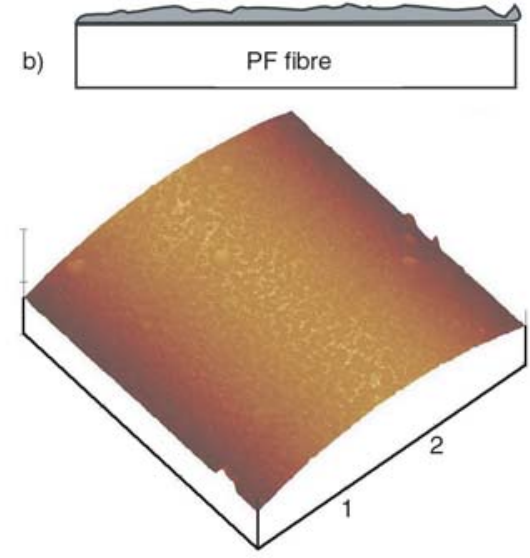

e)

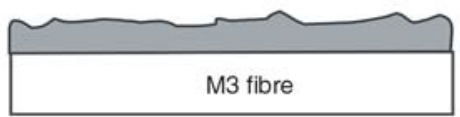

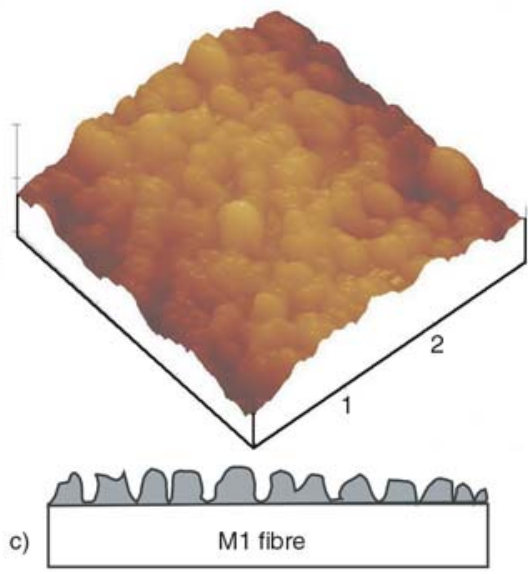

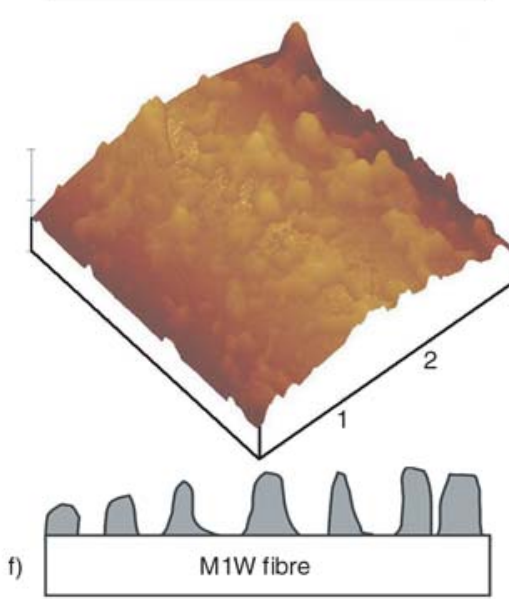

Figure 2. AFM height images and schematic topographies of PP compatibly sized GFs in comparison with only APS and only PP dispersion sized GFs. For all images, the $\mathrm{Z}$ data scale is $250 \mathrm{~nm}$, the scan size is $3 \times 3 \mu \mathrm{m}$

ence in surface roughness for differently sized GFs could be related to the surface tension difference of sizing constituents and the high melting point of PP particles. $\gamma$-APS solution has a higher surface tension $(64 \sim 68 \mathrm{mN} / \mathrm{m})$ compared to PP dispersion $(33.7 \mathrm{mN} / \mathrm{m})$, the wetting ability of $\gamma$-APS solution on the as-spun GFs was not at the same level as that of PP dispersion. As a result of this, the surface of $\gamma$-APS solution pre-sized GFs can not be regarded as chemically homogeneous as the surface of PP dispersion pre-sized GFs. Therefore, the further pickup of PP dispersion on the $\gamma$-APS pre-sized GFs preferentially took place on the locations of better wettability, causing the segregation of PP dispersion on specific locations. Additionally, the melting point of PP particles of the PP dispersion used is about $163^{\circ} \mathrm{C}$ which is higher than the drying temperature of sized GF bobbins, therefore the resulting morphology was mostly retained during the drying, thus the M1 and M1W fibres have rougher surface compared to PF and M2 fibres (cf. Figure 2). The mixture of $\gamma$-APS and PP dispersion has a surface tension of about $35.3 \mathrm{mN} / \mathrm{m}$, this is quite close to the surface tension of pure PP dispersion, hence the mixture could also homogeneously wet the surface of the as-spun GF and the resulting M3 fibre has a smooth surface.

Dynamic contact angle measurements of single fibres using water as measurement liquid were performed to evaluate the hydrophobicity of sized GFs. Advancing contact angle $\left(\theta_{a}\right)$, receding contact angle $\left(\theta_{r}\right)$ and hysteresis $\left(\theta_{a}-\theta_{r}\right)$ of all sized GFs are summarized in Table 1 . It is noted that $\theta_{a}$ of APS fibre is about $83.5^{\circ}$. This value is higher than the expected one $\left(40-68^{\circ}\right)[40,41]$ but still reasonable basing on following two reasons. (i) It was proposed that the electron pair on the amine nitrogen could point toward the glass surface, sideways, or toward free air [3, 26-28, 34, 42-44]. (ii) Using the combination of XPS and time-offlight secondary ion mass spectroscopy (ToFSIMS), Jones and coworkers revealed that a small amount of polydimethylsiloxane may be introduced into $\gamma$-APS in production and transferred onto the 
surface of only $\gamma$-APS sized GF $[30,31]$. In the case of PF fibre, a more hydrophilic surface was formed, $\theta_{a}$ and $\theta_{r}$ are 58.1 and $41.6^{\circ}$, respectively. This arises from the polar nature of the surface of PP particles which are stabilized with alkyl polyethylene glycol ether and anionic carboxylate group of MAH- $g$-PP. $\theta_{a}$ of M1 and M2 fibres is in the range of 73 to $77^{\circ}$ and smaller than that of M3 fibre $\left(84.5^{\circ}\right)$. It suggests that under standard conditions two-stage technology resulted in sized GFs with more hydrophilic surface in comparison with onestage technology. Increasing the first applicator roll speed (M1W fibre) obtained a little bit more hydrophobic surface compared to M1 fibre, $\theta_{a}$ increases from 77.7 to $84.2^{\circ}$, which likely correlates with the increased sizing uptake. On the other hand, the hysteresis increases too, which most likely is due to the rougher surface of M1W fibre when the similarity in the surface chemical composition (see XPS results) between M1 and M1W fibres is taken into consideration.

Besides surface topography and hydrophobicity, the chemical composition and the functional groups of the outermost surface of sizings are also of great importance in determining GF-PP interaction mechanisms, which can affect the GF-matrix adhesion strength level. Hence, XPS was used to determine the surface compositions of sized GFs, while Zetapotential measurements were used to derive information about the functional groups at the outermost surface of sized GFs.

The normalized surface compositions of sized GFs are calculated using $\mathrm{Ca}$ as reference and are presented in Table 2. Ca was used as reference instead of $\mathrm{Si}$, since the $\mathrm{C} / \mathrm{Si}$ ratios for all sized GFs are below 10 (cf. Table 2), which is indicative of thin and/or inhomogeneous sizing coverage of the whole GF-surface [35]. It is noted that $\gamma$-APS sized fibre has high $\mathrm{Ca}, \mathrm{B}$, and $\mathrm{Al}$ contents, suggesting that the sizing of APS fibre is very thin when the smooth and good coverage surface of APS fibre (cf. Figure 2) is taken into consideration. Moreover, the high $\mathrm{N}$ content of APS fibre confirms the formation of the $\gamma$-APS based sizing layer on the surface of GF. Compared to APS fibre, PF fibre possesses higher $\mathrm{C}$ and $\mathrm{Na}$ contents but lower $\mathrm{N}$ content as well as lower $\mathrm{Ca}$, B, and Si contents. Additionally, $\mathrm{PF}$ fibre has about thirteen times higher $\mathrm{C} / \mathrm{Ca}$ ratio and one time higher $\mathrm{C} / \mathrm{Si}$ ratio while the $\mathrm{Si} / \mathrm{Ca}$ ratio drops to 3.3. These indicate that the sizing of PF fibre is still relatively thin but thicker than that of APS fibre. The presence of $\mathrm{N}$ atoms on the surface of PF fibre can be attributed to small amine molecule additives observed by NMR analysis on the acetone soluble part of PP dispersion (data not shown here) or the contamination from air. The average surface compositions of M1 and M1W fibres are quite similar, the main difference is that M1W fibre has a higher Ca content, this may be related to the rougher surface of M1W fibre (cf. Figure 2). Correspondingly, the $\mathrm{O} / \mathrm{Ca}, \mathrm{C} / \mathrm{Ca}$ and $\mathrm{Si} / \mathrm{Ca}$ ratios of M1W fibre are lower than those of M1 fibre. On the other hand, the N/Ca ratio of M1W fibre is quite close to that of M1 fibre, one can conclude that increasing the rotation speed of the first applicator increased the pickup of $\gamma$-APS. This is verified by the Zeta-potential stated below (cf. Figure 3). Compared to M1 and M1W fibres, M2 fibre exhibits reduced $\mathrm{C}$ content and increased

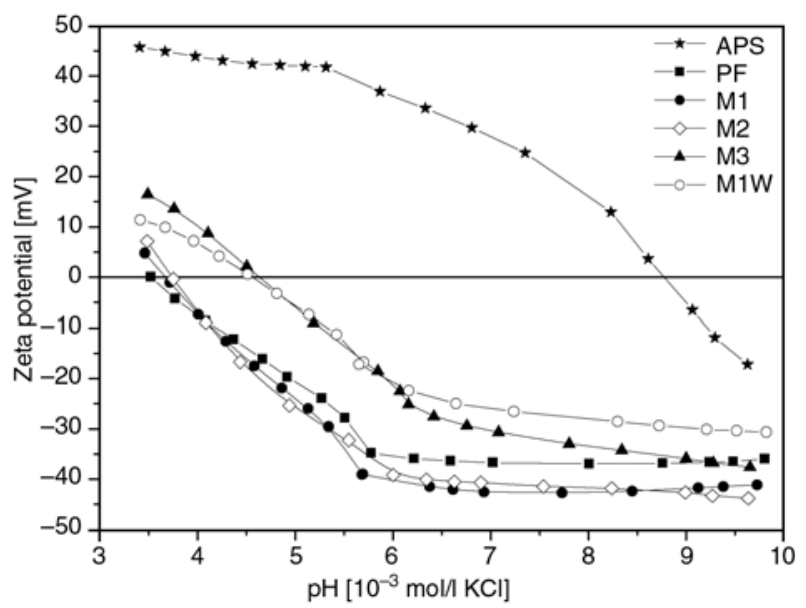

Figure 3. Zeta-potential as a function of $\mathrm{pH}$ for differently sized glass fibres

Table 2. Absolute and normalized average surface compositions (in at\%) of sized glass fibres

\begin{tabular}{|l|c|c|c|c|c|c|c|c|c|c|c|c|c|c|c|}
\hline \multicolumn{1}{|c|}{$\mathbf{G F}$} & $\mathbf{N a}$ & $\mathbf{O}$ & $\mathbf{N}$ & $\mathbf{C a}$ & $\mathbf{C}$ & $\mathbf{B}$ & $\mathbf{S i}$ & $\mathbf{A l}$ & $\mathbf{M g}$ & $\mathbf{N a} / \mathbf{C a}$ & $\mathbf{O} / \mathbf{C a}$ & $\mathbf{N} / \mathbf{C a}$ & $\mathbf{C} / \mathbf{C a}$ & $\mathbf{S i} / \mathbf{C a}$ & $\mathbf{C} / \mathbf{S i}$ \\
\hline APS & 0.2 & 39.9 & 2.2 & 4.0 & 30.4 & 3.1 & 15.4 & 3.6 & 1.2 & 0.05 & 10.0 & 0.55 & 7.6 & 3.8 & 2.0 \\
\hline PF & 0.7 & 34.7 & 0.5 & 3.3 & 43.8 & 2.2 & 10.9 & 3.4 & 0.6 & 0.21 & 10.5 & 0.15 & 13.3 & 3.3 & 4.0 \\
\hline M1 & 0.3 & 23.2 & 0.7 & 1.9 & 62.2 & 1.3 & 7.5 & 2.1 & 0.8 & 0.15 & 12.2 & 0.37 & 32.7 & 3.9 & 8.3 \\
\hline M2 & 0.3 & 28.3 & 0.6 & 2.7 & 53.5 & 1.6 & 10.2 & 2.0 & 0.8 & 0.11 & 10.5 & 0.22 & 19.8 & 3.8 & 5.2 \\
\hline M3 & 0.4 & 28.3 & 1.4 & 2.0 & 61.7 & 1.4 & 7.9 & 2.0 & 0.8 & 0.20 & 14.2 & 0.70 & 30.8 & 4.0 & 7.8 \\
\hline M1W & 0.3 & 21.9 & 0.8 & 2.5 & 63.3 & 1.2 & 7.3 & 2.0 & 0.7 & 0.12 & 8.8 & 0.32 & 25.3 & 2.9 & 8.7 \\
\hline
\end{tabular}


$\mathrm{Si}$ as well as the least amount of $\mathrm{N}$ content on the surface. Correspondingly, the normalized atom contents dropped except the $\mathrm{Si} / \mathrm{Ca}$ ratio. This observation is interesting since it was expected that $\gamma$ APS based oligo- or polysiloxanes would enrich in the outermost surface of M2 fibre, which was spun by applying $\gamma$-APS solution at the second stage. It is indicative of possible migration of $\gamma$-APS based oligo- or polysiloxanes towards GF/sizing interface, which is confirmed by EKA. M3 fibre shows the highest $\mathrm{N}$ content and N/Ca ratio of 0.70 . Taken into account its smooth surface and high LOI value, it is sure that a thicker sizing with homogeneous coverage was formed on M3 fibre when the complete sizing formulation was applied using onestage technology.

Compared to XPS which reveals the average chemical composition for $8 \mathrm{~nm}$ information depth with a take-off-angle of $90^{\circ}$, EKA can provide indirect information of functional groups on the outermost surface of sizing in our case by measuring the Zetapotential as a function of $\mathrm{pH}$ for differently sized GFs (shown in Figure 3). It is widely known that the IEP of non-sized or water sized E-glass is around 2 due to the enrichment of acidic silanol groups on the surface [45]. Compared to non-sized E-glass, APS fibre at the native $\mathrm{pH}$ of 5.7 has a positive Zeta-potential, which is related to the protonation of amino groups, meanwhile the IEP of APS fibre shifts to $\mathrm{pH} 8.5$ owing to the basic amino groups. On the other hand, the IEP of APS fibre is lower than the $\mathrm{pKa}$ of aminopropyl group (9.8 10.6), indicating that the acidic silanol groups of either GF surface or $\gamma$-APS based components are still present on the APS fibre surface. The IEP of PF fibre shifts to $\mathrm{pH}$ of 3.5 compared to that of nonsized GFs, which is very close to the IEP of PP dispersion (Figure 1b), suggesting a good coverage of PP film former on as-spun GFs. The application of complete sizing formulation on the GF shifts the IEP further to more basic values of about $\mathrm{pH} 4.6$, which is also quite close to the IEP of aqueous sizing. The low IEP value of M3 fibre suggests that the major fraction of outermost surface is PP film former. The driving force for this could be attributed to the good affinity between GF surface silanol groups and $\gamma$-APS based components and the low surface free energy of PP film former. The electrokinetic properties of M1 and M2 fibres are very similar to those of $\mathrm{PF}$ fibre. This is reasonable for M1 fibre since the PP dispersion was applied at the second stage, but it is especially interesting in the case of M2 fibre and it is consistent with XPS and water contact angle measurements that only a small amount of $\gamma$-APS based components was picked up and the adsorbed $\gamma$-APS based components diffused to GF surface through the PP film former coverage. It is noted that the electrokinetic properties of M1W fibre is similar to that of M3 fibre, this is indicative of the increase in the uptake of $\gamma$-APS based components at the first stage by increasing the rotation speed of the first applicator. Another possible explanation is that the low coverage of PP film former on the surface of M1W fibre could expose the $\gamma$-APS based components preferably adsorbed on the surface of GF to the medium.

Based on the above investigations, the formation mechanism of sizing for different sizing application technologies is briefly outlined in following. For one-stage technology, the mixture of $\gamma$-APS and PP dispersion has low surface tension and the highest concentration, thus leads to sized GFs with the highest LOI and smooth surface. Meanwhile, the difference in the nature for $\gamma$-APS and PP dispersion causes $\gamma$-APS based components enrichment in the GF/sizing interface and PP dispersion domination in the sizing/air interface, thus the IPN of $\gamma$ APS based components and PP dispersion is created, which is confirmed by our previous work [36]. In the case of two-stage technology, applying $\gamma$-APS solution at the first stage with normal applicator rotation speed leads to the extreme uptake of $\gamma$-APS, which is then mainly confined in the vicinity of sizing/GF interface and can not diffuse outwards to sizing/air interface due to the good affinity between $\gamma$-APS and GFs. However, with increased applicator rotation speed, the uptake of $\gamma$-APS is enhanced resulting in the formation of IPN of $\gamma$ APS based components and PP dispersion. On the other hand, applying $\gamma$-APS solution at the second stage, $\gamma$-APS based components can diffuse towards the sizing/ GF interface driven by the good affinity between $\gamma$-APS and GFs, promoting the formation of the IPN of $\gamma$-APS based components and PP dispersion. 


\subsection{Mechanical properties of unidirectional composite materials}

The effect of the sizing structure on GF-matrix adhesion strength was studied by transverse tensile test on unidirectional GF reinforced PP (UD GF/ PP) made from on-line commingled GF/PP- hybrid yarn of 50 vol.\% GF, since the transverse tensile test is very sensitive to the interfacial bonding between GF and matrix. Figure 4 clearly shows that the sizing structure has a significant influence on the mechanical properties of UD GF/PP composites. Two-stage technology using standard conditions could not obtain UD GF/PP composites with transverse tensile strength comparable to UD GF/ PP based on one-stage technology, for the latter one the strong GF-matrix adhesion strength relates to the high LOI and the IPN of $\gamma$-APS based polysiloxane and PP film former of M3 fibre [29, 35]. Applying $\gamma$-APS solution at the first stage resulted in composites with transverse tensile strength of 4.2 $\mathrm{MPa}$ accompanied by $0.3 \%$ elongation at break. This extremely low transverse tensile strength value suggests a poor GF-matrix adhesion strength, which is mainly due to the absence of covalent bonding between matrix and GF. Applying $\gamma$-APS solution at the second stage improved the GFmatrix adhesion, the transverse tensile strength increased up to $14.1 \mathrm{MPa}$, this value is still low compared to that of the composite based on onestage technology. However, it evidences that $\gamma$-APS based components could migrate towards the sizing/GF interface and condense there leading to the formation of covalent bonds, although the intensity or the density of such covalent bonds is still low. The transverse tensile strength of M1W/ PP composites increases up to $20.5 \mathrm{MPa}$, the elongation at break also raises to $1.2 \%$, these values are still

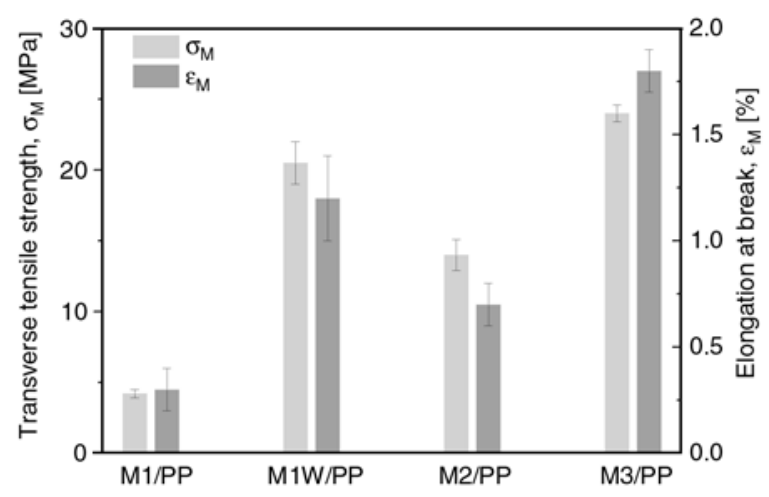

Figure 4. Transverse tensile strength and elongation at break of UD GF/PP composites lower but quite close to those of M3/PP composites. It suggests that increasing the rotation speed of applicator resulted in enhanced intensity of covalent bond. On the other hand, the increased standard deviation of transverse tensile strength and elongation at break relates to the rough surface of M1W fibre.

\section{Conclusions}

In order to achieve a better understanding of the sizing structure formation and its influence on the fibre-matrix adhesion strength, 3-aminopropyltriethoxysilane ( $\gamma$-APS) and polypropylene (PP) dispersion were separately applied on as-spun glass fibres (GFs) at different stages and with different sequences. The surface properties of differently sized GFs as well as the transverse tensile strength of the corresponding unidirectional (UD) GF/PP composites were studied. It was found that the sizing application conditions have a great effect on the formation of sizing structure and, consequently, the GF-matrix adhesion strength. For two-stage technology by applying $\gamma$-APS solution at the first stage with sizing application conditions commonly used in industrial production (referred to as standard conditions), an extremely poor GF-matrix adhesion strength was observed due to the low uptake of $\gamma$ APS. However, this detrimental effect can be counteracted by increasing the uptake of $\gamma$-APS, the UD GF/PP composites obtained by applying $\gamma$-APS solution at the first stage with increased applicator roll speed achieved mechanical properties a little bit lower compared to composites prepared by onestage sizing application of whole sizing formulation. This is attributed to the enhanced covalent bonding and base-acid interaction between the amino group of $\gamma$-APS and the anhydride group of matrix modifier. On the other hand, applying PP dispersion at the first stage, out of expectation, can obtain better GF-matrix adhesion compared with applying $\gamma$-APS solution at the first stage using standard conditions, even though the uptake of $\gamma$ APS was low at the second stage. This emphasizes the importance of the formation of an interpenetrating network of PP and polysiloxane. In future work will be devoted to better understand the influence of sizing structure on the local interphase properties, such as mechanical and thermal properties, by using nano-indentation and nano-TA. 


\section{Acknowledgements}

RCZ would like to thank Johns Manville and Leibniz Institute of Polymer Research Dresden for funding his stay as postdoc. The authors appreciate Dr. H. Brodowsky, Dr. H. Brünig, Mr. W. Ehrentraut, Dr. S.-L. Gao, Mrs. C. Goltzsche, , Mr. J. Rausch, Dr. S. Schwarz (IPF Dresden e.V), Dr. J. Asrar, Dr. D. Blasini, Dr. A. Ferryman, and Dr. K. Gleich (JMTC) for their experimental assistance and helpful discussions.

\section{Abbreviation list}

\begin{tabular}{|l|l|}
\hline AFM & atomic force microscopy \\
\hline$\gamma$-APS & 3-aminopropyltriethoxylsilane \\
\hline EKA & electrokinetic analysis \\
\hline GF & glass fibre \\
\hline IEP & isoelectric point \\
\hline IPN & interpenetrating network \\
\hline LOI & loss-on-ignition \\
\hline MAH-g-PP & maleic anhydride grafted polypropylene \\
\hline PF & polymeric film former \\
\hline PP & polypropylene \\
\hline$R_{q}$ & root mean square roughness \\
\hline$R_{\text {max }}$ & maximum roughness \\
\hline ToF-SIMS & time-of-flight secondary ion mass spectroscopy \\
\hline UD & unidirectional \\
\hline XPS & X-ray photoelectron spectrometer \\
\hline$\theta_{a}$ & advancing contact angle \\
\hline$\theta_{r}$ & receding contact angle \\
\hline
\end{tabular}

\section{References}

[1] Kim J-K., Mai Y-W.: High strength, high fracture toughness fibre composites with interface control - A review. Composites Science and Technology, 41, 333-378 (1991). DOI: $10.1016 / 0266-3538(91) 90072-W$

[2] Pukánszky B.: Interfaces and interphases in multicomponent materials: Past, present, future. European Polymer Journal, 41, 645-662 (2005).

DOI: $10.1016 / j$. eurpolymj.2004.10.035

[3] Ishida H.: A review of recent progress in the studies of molecular and microstructure of coupling agents and their functions in composites, coatings and adhesive joints. Polymer Composites, 5, 101-123 (1984). DOI: $\underline{10.1002 / p c .750050202}$

[4] Drzal L-T., Rich M-J., Lloyd P-F.: Adhesion of graphite fibers to epoxy matrices: I. The role of fiber surface treatment. The Journal of Adhesion, 16, 1-30 (1983).

DOI: $10.1080 / 00218468308074901$

[5] Ishikawa T., Yamaoka H., Harada Y., Fujii T., Nagasawa T.: A general process for in situ formation of functional surface layers on ceramics. Nature, 416, 64-67 (2002). DOI: $\underline{10.1038 / 416064 a}$
[6] Munz M., Sturm H., Schulz E., Hinrichsen G.: The scanning force microscope as a tool for the detection of local mechanical properties within the interphase of fibre reinforced polymers. Composites Part A: Applied Science and Manufacturing, 29, 1251-1259 (1998). DOI: $\underline{10.1016 / \mathrm{S} 1359-835 X(98) 00077-3}$

[7] Mai K., Mäder E., Mühle M.: Interphase characterization in composites with new non-destructive methods. Composites Part A: Applied Science and Manufacturing, 29, 1111-1119 (1998).

DOI: $10.1016 / \mathrm{S} 1359-835 X(98) 00092-X$

[8] Gao S-L., Mäder E.: Characterisation of interphase nanoscale property variations in glass fibre reinforced polypropylene and epoxy resin composites. Composites Part A: Applied Science and Manufacturing, 33, 559-576 (2002). DOI: $\underline{10.1016 / \mathrm{S} 1359-835 \mathrm{X}(01) 00134-8}$

[9] Bergeret A., Bozec M-P., Quantin J-C., Crespy A., Gasca J-P., Arpin M.: Study of interphase in glass fiber-reinforced poly(butylene terephthalate) composites. Polymer Composites, 25, 12-25 (2004). DOI: $10.1002 / p c .20001$

[10] Feuillade V., Bergeret A., Quantin J-C., Crespy A.: Relationships between the glass fibre sizing composition and the surface quality of sheet moulding compounds (SMC) body panels. Composites Science and Technology, 66, 115-127 (2006).

DOI: 10.1016/j.compscitech.2005.05.009

[11] Feuillade V., Bergeret A., Quantin J-C., Crespy A.: Characterisation of glass fibres used in automotive industry for SMC body panels. Composites Part A: Applied Science and Manufacturing, 37, 1536-1544 (2006).

DOI: 10.1016/j.compositesa.2005.11.010

[12] Mäder E., Pisanova E.: Interfacial design in fiber reinforced polymers. Macromolecular Symposia, 163, 189-212 (2001).

DOI: 10.1002/1521-3900(200101)163:1<189::AIDMASY189>3.0.CO;2-8

[13] Jones F-R.: Interphase formation and control in fibre composite materials. Key Engineering Materials, 116117, 41-60 (1996).

DOI: 10.4028/www.scientific.net/KEM.116-117.41

[14] Mäder E., Pisanova E.: Characterization and design of interphases in glass fiber reinforced polyproplyene. Polymer Composites, 21, 361-368 (2000). DOI: $10.1002 / p c .10194$

[15] Jensen R. E., McKnight S. H.: Inorganic-organic fiber sizings for enhanced energy absorption in glass fiberreinforced composites intended for structural applications. Composites Science and Technology, 66, 509521 (2006). DOI: $10.1016 /$ j.compscitech.2005.06.004 
[16] Gao X., Jensen R-E., Li W., Deitzel J., McKnight SH., Gillespie J-W.: Effect of fiber surface texture created from silane blends on the strength and energy absorption of the glass fiber/epoxy interphase. Journal of Composite Materials, 42, 513-534 (2008). DOI: $\underline{10.1177 / 0021998307086203}$

[17] Danner K-M., Dey M., McAllister Q-P., Barsotti R-J., Kissounko D-A.: Synergetic behavior of low $T_{g}$ polybutadiene polymers and polysiloxanes as components for glass fiber sizing in composite materials. Journal of Applied Polymer Science, 118, 841-848 (2010). DOI: 10.1002/app.32333

[18] Mäder E., Moos E., Karger-Kocsis J.: Role of film formers in glass fibre reinforced polypropylene - New insights and relation to mechanical properties. Composites Part A: Applied Science and Manufacturing, 32, 631-639 (2001). DOI: $\underline{10.1016 / \mathrm{S} 1359-835 \mathrm{X}(00) 00156-1}$

[19] Zinck P., Mäder E., Gerard J-F.: Role of silane coupling agent and polymeric film former for tailoring glass fiber sizings from tensile strength measurements. Journal of Materials Science, 36, 5245-5252 (2001).

DOI: 10.1023/A:1012410315601

[20] Frenzel H., Mäder E.: Influence of different interphases on the mechanical properties of fiber-reinforced polymers. Progress in Colloid and Polymer Science, 101, 199-202 (1996). DOI: $\underline{10.1007 / \mathrm{BFb} 0114470}$

[21] Thomason J-L., Adzima L-J.: Sizing up the interphase: An insider's guide to the science of sizing. Composites Part A: Applied Science and Manufacturing, 32, 313-321 (2001). DOI: $10.1016 / \mathrm{S} 1359-835 \mathrm{X}(00) 00124-\mathrm{X}$

[22] Thomason J-L., Schoolenberg G-E.: An investigation of glass fibre/polypropylene interface strength and its effect on composite properties. Composites, 25, 197-203 (1994).

DOI: 10.1016/0010-4361(94)90017-5

[23] Frenzel H., Bunzel U., Häßler R., Pompe G.: Influence of different glass fiber sizings on selected mechanical properties of PET/glass composites. Journal of Adhesion Science and Technology, 14, 651-660 (2000). DOI: $10.1163 / 156856100742906$

[24] Lariviere D., Krawczak P., Tiberi C., Lucas P.: Interfacial properties in commingled yarn thermoplastic composites. Part II: Influence on crack initiation and propagation. Polymer Composites, 25, 589-600 (2004).

DOI: $\underline{10.1002 / p c .20053}$

[25] Lariviere D., Krawczak P., Tiberi C., Lucas P.: Interfacial properties in commingled yarn thermoplastic composites. Part I: Characterization of the fiber/matrix adhesion. Polymer Composites, 25, 577-588 (2004). DOI: $10.1002 / \mathrm{pc} .20052$
[26] Ishida H., Naviroj S., Tripathy S-K., Fitzgerald J-J., Koenig J-L.: The structure of an aminosilane coupling agent in aqueous solutions and partially cured solids. Journal of Polymer Science: Polymer Physics Edition, 20, 701-718 (1982).

DOI: $\underline{10.1002 / \mathrm{pol} .1982 .180200412}$

[27] Ishida H., Koenig J-L.: Fourier transform infrared spectroscopic study of the structure of silane coupling agent on E-glass fiber. Journal of Colloid and Interface Science, 64, 565-576 (1978). DOI: 10.1016/0021-9797(78)90398-3

[28] Naviroj S., Culler S-R., Koenig J-L., Ishida H.: Structure and adsorption characteristics of silane coupling agents on silica and E-glass fiber; Dependence on $\mathrm{pH}$. Journal of Colloid and Interface Science, 97, 308-317 (1984).

DOI: 10.1016/0021-9797(84)90301-1

[29] Liu X-M., Thomason J-L., Jones F-R.: XPS and AFM study of interaction of organosilane and sizing with Eglass fibre surface. The Journal of Adhesion, 84, 322338 (2008).

DOI: $10.1080 / 00218460802004386$

[30] Wang D., Jones F-R.: Surface analytical study of the interaction between $\gamma$-amino propyl triethoxysilane and E-glass surface. Part II X-ray photoelectron spectroscopy. Journal of Materials Science, 28, 2481-2488 (1993).

DOI: $10.1007 / \mathrm{BF} 01151683$

[31] Wang D., Jones F-R., Denison P.: Surface analytical study of the interaction between $\gamma$-amino propyl triethoxysilane and E-glass surface. Part I: Time-offlight secondary ion mass spectrometry. Journal of Materials Science, 27, 36-48 (1992).

DOI: $10.1007 / \mathrm{BF} 02403641$

[32] Benkoski J-J., Kramer E-J., Yim H., Kent M-S., Hall $\mathrm{J} .:$ The effects of network structure on the resistance of silane coupling agent layers to water-assisted crack growth. Langmuir, 20, 3246-3258 (2004). DOI: $10.1021 / \mathrm{la035920k}$

[33] Plonka R., Mäder E., Gao S-L., Bellmann C., Dutschk V., Zhandarov S.: Adhesion of epoxy/glass fibre composites influenced by aging effects on sizings. Composites Part A: Applied Science and Manufacturing, 35, 1207-1216 (2004).

DOI: $10.1016 /$ j.compositesa.2004.03.005

[34] Darbha S., Mittal K-L.: Effect of pH of silane solution on the adhesion of polyimide to a silica substrate. Journal of Applied Polymer Science, 29, 2039-2043 (1984).

DOI: $10.1002 / a p p .1984 .070290612$

[35] Thomason J-L., Dwight D-W.: The use of XPS for characterisation of glass fibre coatings. Composites Part A: Applied Science and Manufacturing, 30, 14011413 (1999). DOI: $\underline{10.1016 / \mathrm{S} 1359-835 \mathrm{X}(99) 00042-1}$ 
[36] Zhuang R-C., Burghardt T., Mäder E.: Study on interfacial adhesion strength of single glass fibre/polypropylene model composites by altering the nature of the surface of sized glass fibres. Composites Science and Technology, 70, 1523-1529 (2010).

DOI: $\underline{10.1016 / j . c o m p s c i t e c h .2010 .05 .009}$

[37] Mäder E., Rothe C., Gao S-L.: Commingled yarns of surface nanostructured glass and polypropylene filaments for effective composite properties. Journal of Materials Science, 42, 8062-8070 (2007).

DOI: $10.1007 / \mathrm{s} 10853-006-1481-\mathrm{x}$

[38] Reinhardt S., Steinert V., Werner K.: Investigations on the dissociation behaviour of hydrolyzed alternating copolymers of maleic anhydride and propene-I. Potentiometric titrations. European Polymer Journal, 32, 935-938 (1996).

DOI: 10.1016/0014-3057(96)00028-6

[39] Schweiss R., Welzel P-B., Werner C., Knoll W.: Dissociation of surface functional groups and preferential adsorption of ions on self-assembled monolayers assessed by streaming potential and streaming current measurements. Langmuir, 17, 4304-4311 (2001). DOI: $\underline{10.1021 / \mathrm{la} 001741 \mathrm{~g}}$

[40] Heise A., Menzel H., Yim H., Foster M-D., Wieringa R-H., Schouten A-J., Erb V., Stamm M.: Grafting of polypeptides on solid substrates by initiation of $N$-carboxyanhydride polymerization by amino-terminated self-assembled monolayers. Langmuir, 13, 723-728 (1997). DOI: $10.1021 / \mathrm{la} 960467 \mathrm{~g}$
[41] Bayer T., Eichhorn K-J., Grundke K., Jacobasch H-J.: FTIR spectroscopic studies of interfacial reactions between amino functionalized silicon surfaces and molten maleic anhydride copolymers. Macromolecular Chemistry and Physics, 200, 852-857 (1999).

DOI: 10.1002/(SICI)1521-3935(19990401)200:4 $\leq 852::$ AID-MACP852>3.0.CO;2-V

[42] Lee L-H.: Wettability and conformation of reactive polysiloxanes. Journal of Colloid and Interface Science, 27, 751-760 (1968).

DOI: $10.1016 / 0021-9797(68) 90109-4$

[43] Bascom W-D.: Structure of silane adhesion promoter films on glass and metal surfaces. Macromolecules, 5, 792-798 (1972).

DOI: $10.1021 / \mathrm{ma} 60030 \mathrm{a} 024$

[44] Wu H-F., Dwight D-W., Huff N-T.: Effects of silane coupling agents on the interphase and performance of glass-fiber-reinforced polymer composites. Composites Science and Technology, 57, 975-983 (1997). DOI: $10.1016 / \mathrm{S} 0266-3538(97) 00033-\mathrm{X}$

[45] Rosenholm J-M., Lindén M.: Wet-chemical analysis of surface concentration of accessible groups on different amino-functionalized mesoporous SBA-15 silicas. Chemistry of Materials, 19, 5023-5034 (2007). DOI: $10.1021 / \mathrm{cm} 071289 \mathrm{n}$ 